\title{
Características morfogênicas e estruturais do capim-marandu manejado sob pastejo intermitente com diferentes ofertas de forragem
}

\author{
Daniel Rume Casagrande ${ }^{1}$, Ana Cláudia Ruggieri ${ }^{1}$, Estella Rosseto Janusckiewicz ${ }^{1}$, José \\ Alberto Gomide ${ }^{2}$, Ricardo Andrade Reis ${ }^{1}$, Andre Luis da Silva Valente ${ }^{1}$ \\ ${ }^{1}$ FCAVIUNESP - Via de acesso Prof. Paulo Donaldo Castellane s/n, Jaboticabal, SP. \\ ${ }^{2}$ Departamento de Zootecnia - UFV.
}

RESUMO - Avaliaram-se as características morfogênicas e estruturais do dossel de Brachiaria brizantha, cv. Marandu, sob pastejo intermitente no período chuvoso, em diferentes ofertas de forragem e ciclos de pastejo. O delineamento experimental foi em blocos ao acaso, em esquema de parcelas subdivididas, com três repetições. Nas parcelas, avaliou-se o efeito das ofertas de forragem (4, 7, 10 e 13\% do PV/dia) e, nas subparcelas, o efeito dos ciclos de pastejo. Todas as variáveis diferiram entre os ciclos de pastejo, comprovando grande influência das condições ambientais sobre as características avaliadas. A taxa de alongamento do colmo e a altura do dossel responderam linear e positivamente ao aumento da oferta de forragem. O número de perfilhos vegetativos nos piquetes com a menor oferta permaneceu constante ao longo de todo o período experimental, no entanto, nos piquetes com as demais ofertas, atingiu valores mais elevados nos ciclos intermediários. A densidade de perfilhos reprodutivos e totais ajustou-se ao modelo quadrático de acordo com a oferta de forragem. Pastos manejados com ofertas de forragem próximas a 4\% PV/dia têm menor alongamento de colmos e tendem a reduzir as perdas por senescência. As variáveis ambientais exercem maior influência sobre as características morfogênicas e estruturais em comparação a ações de manejo como a oferta de forragem.

Palavra-chave: alongamento de colmo, altura do dossel, Brachiaria brizantha, ciclos de pastejo, intensidade de pastejo, morfogênese

\section{Morphogenetic and structural traits of Marandugrass pasture under continuous grazing with different forage supply}

\begin{abstract}
It was evaluated morphogenetic and structural characteristics of the canopy of Brachiaria brizantha cv. Marandu under continuous grazing during the wet season, in different forage supplies and grazing cycles. A random block experimental design was used in a split-plot scheme with three replicates. It was evaluated in the plots the plots, the effects of forage supplies (4,7, 10 and 13\% BW/day) and in the subplots, the effects of grazing cycles were evaluated. All the variables differed among grazing cycles, proving the great influence of environmental conditions on the evaluated characteristics. Stem elongation rate and canopy height showed linear and positive responses to the increase on forage supply. Number of vegetative tillers in the plots with the lowest supply was constant over the whole experimental period, however, in the plots with the other supplies, tillers reached highest values in the intermediate cycles. Density of total and reproductive tillers was fitted to the quadratic model accordingly to the forage supply. Pastures managed with forage supplies close to $4 \% \mathrm{BW} /$ day showed lower stem elongation and they tend to reduce loses caused by senescence. Environmental variables affect morphogenetic and structural characteristics more than management with forage supply does.
\end{abstract}

Key Words: Brachiaria brizantha, canopy height, grazing cycles, grazing intensity, morphogenesis, stem elongation

\section{Introdução}

Na busca pela correta condução dos animais em pastejo, é de grande importância o conhecimento do processo de transformação da forragem em produto animal e, principalmente, da dinâmica dos processos de crescimento e desenvolvimento das plantas que compõem a pastagem e suas respostas morfofisiológicas aos fatores interferentes. Entre esses fatores, destaca-se a intensidade de pastejo, que afeta diretamente as taxa de acúmulo de forragem (Parsons et al., 1983).

As gramíneas tropicais, como as dos gêneros Panicum e Brachiaria, apresentam, diferentemente das de clima temperado, intenso alongamento de colmo, mesmo no

Recebido em 27/2/2009 e aprovado em 23/9/2009.

Correspondências devem ser enviadas para: daniel_casagrande@yahoo.com.br 
estádio vegetativo, o que resulta em estreitamento da relação folha/colmo (Cândido et al., 2005) e redução no consumo de forragem pelos animais. O conhecimento de como a intensidade e frequência de desfolha interferem na características morfogênicas e estruturais é fundamental para a redução dos efeitos negativos do alongamento do colmo. Da Silva \& Nascimento Jr. (2007) enfatizaram a importância do uso da morfogênese em ensaio de pesquisa com pastagens. Os mesmos autores destacaram também a inclusão no diagrama apresentado por Chapman \& Lemaire (1993) de uma quarta característica morfogênica, o alongamento de colmo, em plantas forrageiras de clima tropical e, ainda, a relação de todas essas variáveis na interface planta-animal.

Objetivou-se com este trabalho avaliar as características estruturais e morfogênicas do dossel de Brachiaria brizantha, cv. Marandu, manejado em quatro ofertas de forragem, em regime de desfolha intermitente, ao longo da estação chuvosa.

\section{Material e Métodos}

O experimento foi conduzido no setor de forragicultura da FCAV/Unesp, câmpus de Jaboticabal, durante o período de outubro de 2005 a abril de 2006. O clima de Jaboticabal é classificado como subtropical do tipo CWA de Köppen, com temperaturas mínima, média e máxima de 19,8, 24,5 e $32,5^{\circ} \mathrm{C}$, respectivamente, durante o período experimental. Os dados de precipitação obtidos durante o trabalho (Figura 1) foram extraídos de um conjunto de dados pertencentes ao acervo de agrometeorologia do Departamento de Ciências Exatas.

O solo da área experimental foi classificado como Latossolo Vermelho Distrófico, típico textura argilosa (Andrioli \& Centurion, 1999) e a pastagem foi estabelecida em novembro de 2003. Durante o período experimental,

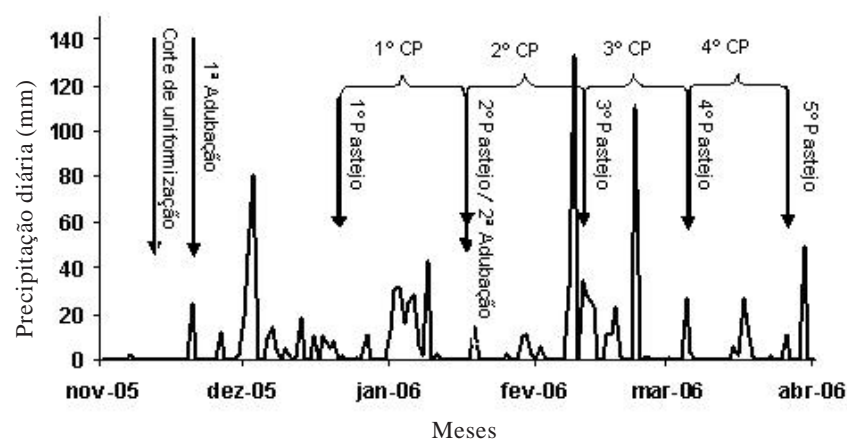

Figura 1 - Precipitação pluvial diária durante cada ciclo de pastejo (CP). Jaboticabal, São Paulo. foram observadas as seguintes características químicas do solo; pHde 5,2;26g/dm ${ }^{3} \mathrm{deMO} ; 12 \mathrm{mg} / \mathrm{dm}^{3} \mathrm{deP} ; 5,3 \mathrm{mmol}_{\mathrm{C}} / \mathrm{dm}^{3}$

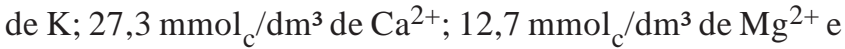
$60 \%$ de $\mathrm{V}$.

A adubação de manutenção da área experimental consistiu da aplicação de 140, 30 e 100 kg/ha/ano de N; $\mathrm{P}_{2} \mathrm{O}_{5}$ e $\mathrm{K}_{2} \mathrm{O}$, na forma de ureia, superfosfato simples e de cloreto de potássio, respectivamente. A adubação com fósforo e potássio foi realizada de uma só vez no início do experimento e a adubação com nitrogênio foi dividida em duas aplicações (Figura1). A fim de uniformizar a vegetação, antes do início do período experimental, realizou-se corte de uniformização a $10 \mathrm{~cm}$ do nível do solo, por meio de corte mecânico da plantas em toda área experimental (Figura 1).

Foram estudadas quatro ofertas de forragem, correspondentes a 4, 7, 10 e 13\% do PV. O ajuste da carga animal baseou-se na divisão da a massa de forragem presente em cada piquete no momento do pastejo $(\mathrm{kg} /$ piquete de forragem) pela oferta de forragem desejada (\% do PV) dividida por 100. O número de animais foi determinado pela divisão da carga animal pelo peso médio dos mesmos. O delineamento experimental foi em blocos casualizados, com três repetições, totalizando 12 unidades experimentais (piquete). A massa de forragem foi mensurada pelo método de dupla amostragem (Sollenberger \& Cherney, 1995), no qual estimativas destrutivas são associadas à altura do dossel (comprimido) pelo uso do prato ascendente.

O método de pastejo adotado foi de lotação intermitente, com período de descanso de 21 dias, utilizando a técnica de "mob-grazing”, em que os animais entraram na área experimental apenas no momento do pastejo. A área de cada piquete variou de $230 \mathrm{a} 586 \mathrm{~m}^{2}$, inversamente às ofertas de forragens predeterminadas. Esse procedimento foi adotado visando à redução da área experimental e à manutenção o número próximo de animais por parcela para eliminar o efeito de grupo. Para o pastejo foram utilizadas vacas não-lactantes e/ou novilhas da raça Holandesa com aproximadamente $450 \mathrm{~kg}$. O primeiro pastejo ocorreu quando a massa de forragem média foi de $3.500 \mathrm{~kg} / \mathrm{ha}$ em todos os piquetes. Após pesagem dos animais e posterior seleção, os animais foram sorteados em grupos de acordo com a oferta de forragem pretendida e o tamanho do piquete.

No início de cada período de descanso, foram marcados 18 perfilhos em cada piquete para avaliar as características morfogênicas e estruturais da gramínea. Para melhor identificação da localização dos perfilhos, procedeu-se ao alinhamento dos perfilhos delimitados por duas estacas e, em cada piquete, foram alocados três alinhamentos em pontos representativos da condição do relvado. Em cada alinhamento, foram marcados seis perfilhos representativos, 
espaçados de 20 a $30 \mathrm{~cm}$ e identificados com fios coloridos (Bircham \& Hodgson, 1983). A cada ciclo de pastejo, foi marcado um novo grupo de perfilhos para as avaliações.

Em cada ciclo de pastejo, os perfilhos foram examinados duas vezes por semana durante todo o período de descanso e neles foram mesurados: o comprimento de colmo+bainha (mm), delimitado pelo nível do solo até a lígula da última folha completamente expandida; o comprimento das lâminas foliares completamente expandidas (mm), medido da lígula até a extremidade viva da lâmina foliar; e o comprimento das lâminas em expansão (mm), mensurado da lígula da última folha viva até a extremidade da lâmina foliar em expansão. As folhas foram classificadas como expandidas quando apresentavam a lígula visível e mortas quando o limbo foliar estivesse totalmente comprometido pela senescência. As folhas foram consideradas vivas apenas quando estavam completamente expandidas. De posse desses dados, foram quantificadas variáveis morfogênicas e estruturais.

A taxa de aparecimento de folhas (TApF) foi calculada dividindo o número de folhas aparecidas durante o período avaliado pelo período de estudo em dias e graus.dias. Para cálculo em graus-dia, adotou-se a metodologia proposta por Ometto (1981). O filocrono foi calculado pelo inverso da taxa de aparecimento de folhas e o número de folhas vivas (NFV), pela média de todos os perfilhos marcados em cada piquete. A duração de viva das folhas (DVF) foi estimada pela multiplicação do número de folhas vivas pelo filocrono.

O comprimento final de folhas (CFF) foi determinado calculando a média do comprimento das folhas expandidas e inteiras As taxas de alongamento foliar (TAlF) foram obtidas pela diferença entre o comprimento final (último dia de avaliação) e inicial (primeiro dia de avaliação) das folhas em expansão das lâminas foliares de cada perfilho dividido pelo número de dias. O mesmo procedimento foi adotado para estimar o alongamento do colmo (TAlC). As taxas de

(a)

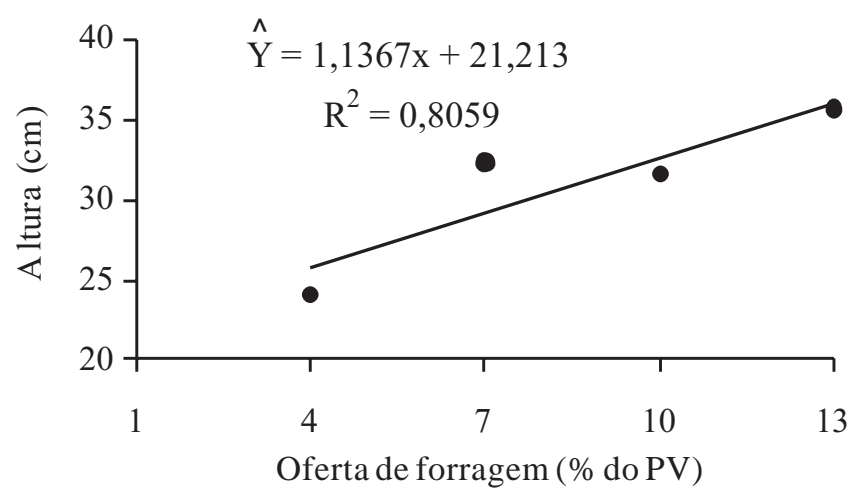

senescência (TS) foram obtidas pela diferença entre comprimento da lâmina foliar, fração verde, inicial e final. Estas características foram expressas em mm/dia/perfilho ou mm/graus-dia/perfilho.

Para avaliação da densidade populacional de perfilhos, foram colhidas, de forma destrutiva, três amostras em cada unidade experimental, cortadas no nível do solo, delimitadas por uma moldura com área conhecida $(0,25 \times 0,25 \mathrm{~cm})$. Depois de colhidas, as amostras foram identificadas e levadas ao laboratório, onde foi efetuada a contagem, separando os perfilhos em duas categorias (vegetativos e reprodutivos) considerando os perfilhos totais o somatório dos perfilhos vegetativos e reprodutivos.

As variáveis-respostas foram submetidas inicialmente ao teste de esfericidade. Para nenhuma dessas variáveis, foi observada significância $(\mathrm{P}>0,10)$ nesse teste. Assim, utilizou-se para análise dos dados um delineamento de parcelas subdivididas com as ofertas de forragem na parcela e os ciclos de pastejo nas subparcelas. Posteriormente realizou-se a análise de variância pelo teste $\mathrm{F}$. As médias foram analisadas pelo teste Tukey a $5 \%$ de probabilidade e avaliadas somente quando encontrado efeito dos ciclos de pastejo ou interação entre oferta de forragem e ciclo de pastejo. Para avaliação do efeito das ofertas de forragem, foi realizada ainda análise de regressão, a 5\% de significância, utilizando-se o pacote estatístico SAS (2002).

\section{Resultados e Discussão}

A altura média do dossel no pré-pastejo aumentou linearmente $(\mathrm{P}<0,01)$ com as ofertas de forragem, isto é, inversamente à intensidade do pastejo (Figura 2).

Aumento da altura do dossel foi também verificado por outros autores em pesquisas com ofertas crescentes de forragem em capins tropicais. Machado et al. (2007)

(b)

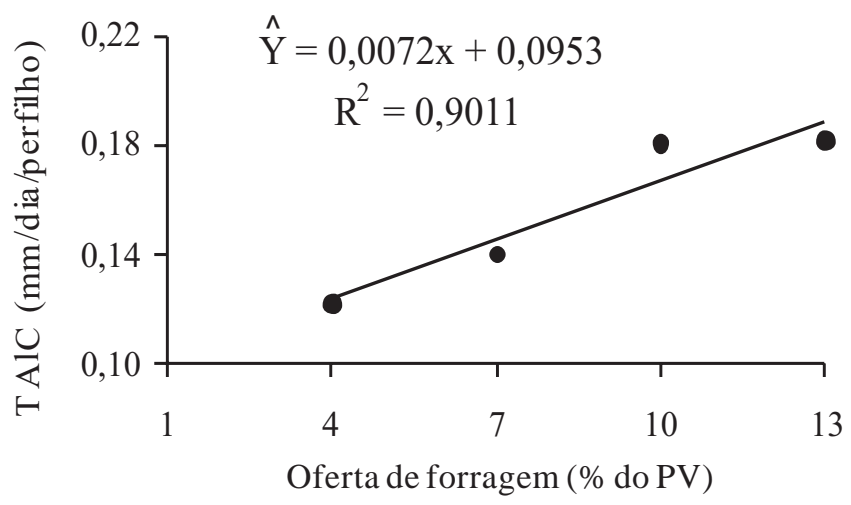

Figura 2 - Altura do dossel (a) e taxa de alongamento de colmo (b) de capim-marandu manejados em quatro ofertas de forragem no período das águas. 
obtiveram valores de 8, 17, 24 e $32 \mathrm{~cm}$ para a altura do dossel em capim-marandu sob lotação contínua em estudo com ofertas de lâminas foliares de 3,7; 7,4; 10,0 e 13\% do peso vivo. Também foi observado efeito dos ciclos de pastejo $(\mathrm{P}<0,0001)$ sobre a altura média do dossel, sem significância da interação entre oferta de forragem e ciclo de pastejo $(\mathrm{P}=0,1479)$. A maior altura do dossel no pré-pastejo foi observada nos últimos dois ciclos, que não diferiram entre si $(\mathrm{P}>0,05)$, e a menor no segundo ciclo de pastejo (Tabela 1 ). Embora a altura no segundo ciclo tenha sido menor que a do primeiro, essa variável aumentou ao longo do período experimental, comprovando efeito cumulativo ao longo do período experimental. A altura do pasto seguiu a mesma tendência observada por Casagrande (2007) em trabalho conduzindo concomitante a este. Esse autor verificou menor massa de forragem, de $3.924 \mathrm{~kg} / \mathrm{ha}$, com a oferta de forragem de $4 \%$ do PV/dia e $5174 \mathrm{~kg} / \mathrm{ha} \mathrm{com}$ a oferta de forragem de 13\% do PV/dia, valores que refletiram em taxas de lotação de 10,4a4,3UA/hanas ofertasde 4e13\%do PV/dia, respectivamente.

A taxa de alongamento da folha (TAlF) não foi afetada pela oferta de forragem $(\mathrm{P}>0,05)$. A média observada foi de $17,5 \mathrm{~mm} /$ dia/perfilho ou 1,57 mm/graus-dia/perfilho. De acordo com Davis (1974), a taxa de alongamento de folha é pouco afetada pela intensidade da desfolhação, sendo observada pequena redução somente pela total desfolha do perfilho. Peternelli (2003) também não observou efeito das intensidades de pastejo na taxa de alongamento de folha em pastagens de Brachiaria decumbens e $B$. brizantha. Barbosa et al. (2002) também não notaram efeito de dois resíduos (2,3 e 3,6 t/ha de MS) no póspastejo sobre a taxa de alongamento de folha em pastagem de capim-tanzânia. Os valores obtidos neste trabalho foram maiores que a média de $12,4 \mathrm{~mm} /$ dia/perfilho encontrada por Sbrissia (2004) no verão em capim-marandu manejado sob lotação contínua com diferentes alturas do dossel. Entretanto, esse autor constatou acréscimo nesta variável nas maiores alturas de pastejo.
A taxa de alongamento de folha variou $(\mathrm{P}<0,0001)$ de acordo com os ciclos de pastejo (Tabela 1), todavia, a interação entre oferta de forragem e ciclo de pastejo não foi significativa $(\mathrm{P}>0,05)$. Essa variável aumentou à medida que os ciclos de pastejo foram se sucedendo e atingiu o maior valor no terceiro ciclo ( $23 \mathrm{~mm} /$ perfilho/dia e 2,10 mm/grausdias/perfilho); no último ciclo foi constatada redução no alongamento de folhas, indicando que as condições ambientais, principalmente precipitação, não foram ideais nesse período (Figura 1). O maior alongamento de folhas nos primeiros ciclos de pastejo, sobretudo no terceiro, pode ser justificado pela maior precipitação, aliada ao efeito da adubação nitrogenada, que tem grande efeito sobre essa variável (Fagundes et al., 2006a).

A taxa de alongamento de colmo (TAlC) aumentou linearmente $(\mathrm{P}<0,01)$ com a oferta de forragem (Figura 2$)$. $\mathrm{O}$ maior alongamento do colmo nas maiores ofertas de forragem pode ser justificado pela maior altura do dossel manejado nestas circunstâncias, provocando sombreamento mútuo dos perfilhos e intensa competição por luz nos dosséis.

Da Silva, S. et al. (2009) estudaram a relação entre a interceptação luminosa (IL) e estrutura do pasto em capimmombaça submetido a diferentes regimes de desfolhação e verificaram aumento da massa de colmo o dossel interceptar 95\% da radiação incidente. Cândido et al. (2005) também demonstraram intensificação do alongamento do colmo a partir do ponto em que seu dossel interceptava $95 \%$ da radiação fotossinteticamente ativa em pastagem de capimmombaça submetido a regime de desfolha intermitente. Da mesma forma, Zeferino (2006), em estudo com pastos de capim-marandu sob lotação intermitente, observou que, quando o período de descanso foi estendido até $100 \%$ de interceptação luminosa, o alongamento de colmo foi maior que nos pastos em que o período de descanso foi interrompido no momento em que o dossel interceptou 95\% da luz incidente. Esse autor observou também que os dosséis atingiram 95\% da luz incidente próximo a $25 \mathrm{~cm}$ de

Tabela 1 - Características morfogênicas e estruturais de perfilhos de capim-marandu sob pastejo intermitente em quatro ciclos de pastejo

\begin{tabular}{|c|c|c|c|c|}
\hline & \multicolumn{4}{|c|}{ Ciclo de pastejo } \\
\hline & 1 & 2 & 3 & 4 \\
\hline Altura (cm) & $29,3 b$ & $23,5 c$ & 33,8 a & $33,2 \mathrm{a}$ \\
\hline Taxa de alongamento de folhas (mm/dia/perfilho) & $15,3 \mathrm{bc}$ & $18,1 \mathrm{~b}$ & $22,9 a$ & $13,7 \mathrm{c}$ \\
\hline Taxa de alongamento de colmos (mm/dia/perfilho) & $0,6 \mathrm{~d}$ & $2,9 \mathrm{a}$ & $2,0 \mathrm{~b}$ & $1,3 c$ \\
\hline Taxa de aparecimento de folhas (folha/dia/perfilho) & $0,08 b$ & $0,11 \mathrm{a}$ & $0,12 \mathrm{a}$ & $0,08 b$ \\
\hline Filocrono (dias/folha/perfilho) & $12,8 \mathrm{a}$ & $9,4 b$ & $9,0 \mathrm{~b}$ & $13,6 \mathrm{a}$ \\
\hline Duração de vida das folhas (dias/folha) & $47,2 \mathrm{ab}$ & $42,3 b$ & $36,8 c$ & $48,6 \mathrm{a}$ \\
\hline Número de folhas vivas (folhas/perfilho) & $3,7 c$ & $4,5 \mathrm{a}$ & $4,1 b$ & $3,6 c$ \\
\hline Comprimento final de folhas (mm) & 198,6 bc & $186,2 \mathrm{c}$ & $223,5 \mathrm{a}$ & $212,8 \mathrm{ab}$ \\
\hline Densidade de perfilhos vegetativos (perfilhos $/ \mathrm{m}^{2}$ ) & $0 \mathrm{c}$ & $47,6 \mathrm{bc}$ & $193,8 \mathrm{a}$ & $81,8 b$ \\
\hline Densidade de pefilhos totais (perfilhos $/ \mathrm{m}^{2}$ ) & $918 c$ & $1671 \mathrm{a}$ & $1742 \mathrm{a}$ & $1292 b$ \\
\hline
\end{tabular}

Médias seguidas da mesma letra minúscula na linha não diferem $(\mathrm{P}>0,05)$ entre si pelo teste Tukey. 
altura e que o nível de $100 \%$ de interceptação foi atingido com $35 \mathrm{~cm}$ de altura. Dessa forma, é possível que neste trabalho, nas maiores ofertas de forragem, a interceptação luminosa pelo dossel tenha atingido valores superiores a $95 \%$, justificando os valores obtidos.

Houve efeito $(\mathrm{P}<0,0001)$ dos ciclos de pastejo sobre as taxas de alongamento de colmo (Tabela 1 ), que foram maiores no segundo e terceiro ciclo de pastejo, com valores de 2,9 e 2,0 mm/dia/perfilho, respectivamente. As maiores taxas obtidas nesses dois períodos são justificadas pela maior densidade populacional de perfilhos (DPPt) e pelo maior número de folhas vivas por perfilho nesse período (Tabela 1), visto que essas duas variáveis têm relação positiva com índice de área foliar (IAF). Desse modo, é possível que ocorra maior índice de área foliar nesses períodos, o que aumentaria a interceptação luminosa, acarretando acentuada competição por luz e refletindo em maior alongamento de colmo. O maior alongamento de colmo no segundo e terceiro ciclos refletiu em aumento da altura dos pastos nos ciclos subsequentes, em decorrência da rejeição desse componente pelos animais. Quando ocorre aumento na proporção de colmos na parte superior do dossel, dificilmente a altura do pasto reduz, visto que esses colmos se tornam um impedimento físico ao pastejo, pela dificuldade em que os animais encontram para consumi-los. As tendências observadas nas taxas de alongamento de colmo, expressas em dias ou em graus-dia, foram semelhantes, assim como para o alongamento de folha.

Não houve efeito significativo das ofertas de forragem, nem dos ciclos de pastejo $(\mathrm{P}>0,05)$, na taxa de senescência foliar, cujo valor médio foi de 3,8 mm/dia/perfilho. Embora não tenha sido constatado efeito significativo da oferta de forragem na senescência, houve tendência de aumento $(\mathrm{P}=0,08)$ dessa variável nos piquetes com ofertas mais generosas. As médias obtidas foram de 3,2 e 4,6 mm/dia/ perfilho nas ofertas de forragem de 4 e $13 \%$ do $\mathrm{PV} / \mathrm{dia}$, respectivamente, que representam aumento de $44 \%$ entre a menor e a maior oferta de forragem estudadas. Esse aumento pode ser atribuído à maior altura do dossel nas ofertas de forragem mais altas (Tabela 1) e, consequentemente, à maior competição por luz nessas parcelas.

Da Silva, S. et al. (2009) mostraram a intensificação do acúmulo de material morto após o dossel interceptar 95\% da radiação fotossinteticamente ativa. Pedreira et al. (2009), em estudo com capim-xaraés a uma altura de resíduo de $15 \mathrm{~cm}$, observaram período de descanso médio de 22 dias para que o dossel interceptasse $95 \%$ da irradiação fotossinteticamente ativa. No entanto, quando se utiliza alta oferta de forragem, há grande sobra de forragem, o que permite que o dossel intercepte $95 \%$ da luz incidente em períodos menores, justificando, a maior senescência nas ofertas mais generosas. Então, o período de descanso deve variar de acordo com a época do ano e a oferta de forragem, de modo que a entrada dos animais em uma pastagem aconteça quando a interceptação luminosa for igual a 95\%. No entanto, há necessidade de trabalhos associando interceptação de luz com oferta de forragem, devido à grande escassez desse tipo de estudo na literatura.

As taxas de aparecimento de folha e os filocronos não responderam às ofertas de forragem $(\mathrm{P}>0,05)$; responderam apenas aos ciclos de pastejo $(\mathrm{P}<0,0001)$. A interação entre oferta de forragem e ciclo de pastejo não foi significativa $(\mathrm{P}>0,05)$. O maior aparecimento de folha ( 0,11 e 0,12 folha/dia/perfilho ou 0,009 e 0,011 folha/grausdias/perfilho) foi observado no segundo e terceiro ciclos de pastejo (Tabela 1), enquanto os menores ocorreram no primeiro e último ciclos ( 0,08 folha/dia/perfilho ou $0,007 \mathrm{e}$ 0,006 folha/graus-dias/perfilho, respectivamente). Essa variação da taxa de aparecimento de folha pode ser atribuída à diferença no alongamento das folhas com os ciclos de pastejo, como discutido anteriormente.

Os menores intervalos para o aparecimento de duas folhas consecutivas e de filocronos, de 9,4 e 9,0 dias no segundo e terceiro ciclo, respectivamente, ocorreram nos ciclos de pastejo intermediários (Tabela 1). Esses valores são maiores que os apresentados por Corsi et al. (1994), de 5,3 a 6,7 dias/folha, na mesma forrageira. No entanto, aproximam-se dos valores obtidos por Gonçalves (2002) para a mesma espécie forrageira sob lotação contínua no período do verão, os quais variaram de 7,4 a 13,0 dias/folha nos meses de novembro a fevereiro, e aos observados por Peternelli (2003) em pastejo intermitente, que variam de 8,1 a 10,7 dias/folha. Esse autor também não observou efeito da oferta de forragem no filocrono. A relação funcional entre taxa de alongamento de folha e o filocrono (Sbrissia, 2004) pode explicar os dados obtidos. Essa relação é de natureza exponencial, de modo que, nas altas taxas de alongamento foliar acima de $13 \mathrm{~mm} /$ dia/perfilho, o filocrono tendeu a se estabelecer por volta de 9 a 12 dias/folha/ perfilho, comprovando que os valores encontrados estão dentro do esperado.

A duração de vida da folha respondeu apenas à variação dos ciclos de pastejo $(\mathrm{P}<0,0001)$, com valores que variaram de 36,8 a 48,6 dias, o menor deles no terceiro ciclo (Tabela 1). Esses valores estão próximos daqueles citados por Corsi et al. (1994) para Brachiaria brizantha, que variaram de 37 a 47 dias. Os valores da duração de vida da folha neste estudo, expressos em graus-dias, variaram de 400 a 547 graus-dias. Hodgson (1990) descreveu o sincronismo entre o aparecimento de uma folha jovem e morte de outra mais velha. Portanto, 
considerando uma planta totalmente desfolhada, a duração de vida da folha é o tempo necessário para que esse sincronismo aconteça. Assim, períodos de descanso mais longos que a duração de vida da folha implicam grandes perdas por senescência. Neste estudo, em todos os ciclos, a vida da folha foi maior que o período de descanso, que foi de 21 dias. Então, a primeira folha expandida após o término do pastejo anterior não entrou em processo de senescência durante o ciclo de pastejo estudado, o que pode explicar as baixas taxas de senescência obtidas neste trabalho. No entanto, houve senescência das folhas que não foram removidas por completo durante o pastejo.

O número de folhas vivas variou apenas entre os ciclos de pastejo $(\mathrm{P}<0,0001)$, uma vez que não foi constatado efeito significativo da oferta de forragem nem da interação entre ciclo de pastejo e oferta de forragem $(\mathrm{P}>0,05)$. Os valores variaram de 3,6 a 4,5 folhas/perfilho e, no segundo e terceiro ciclos, os perfilhos apresentaram maiores números de folhas vivas, 4,5 e 4,1 folhas/perfilho, respectivamente (Tabela 1). Corsi et al. (1994) relataram valor de 7 folhas/ perfilho no capim-marandu, no entanto, esses autores contabilizaram as folhas emergentes, enquanto neste trabalho apenas as folhas expandidas foram consideradas. Assim, há uma proximidade entres os valores relatados, pois o capim-marandu tem em média 1,2 a 1,8 folha emergente/ perfilho. O número de folhas vivas é relativamente constante para cada genótipo, ou seja, quando uma folha senesce, surge uma nova folha no mesmo perfilho (Hodgson, 1990), desde que o perfilho não esteja em crescimento inicial. Nesse caso, o número de folhas expandidas é igual ao número de folhas verdes, porém, quando se inicia o processo de senescência de folhas, o número total de folhas expandidas é progressivamente maior que o de folhas vivas, que tende a se manter constante (Gomide \& Gomide, 2000). O número de folhas vivas é decorrente do limitado tempo de vida da folha e do aparecimento de novas folhas (Chapman \& Lemaire, 1993), que é determinado por características genéticas e pode ser influenciado pelas condições ambientais e principalmente pelo suprimento de nitrogênio (Da Silva, C. et al., 2009). Assim justifica-se o efeito dos ciclos de pastejo, visto que a segunda aplicação de nitrogênio foi realizada no início do segundo ciclo.

O comprimento final da folha não variou entre as ofertas de forragem( $\mathrm{P}>0,05)$, com média geral de $205 \mathrm{~mm}$. Verificou-se, porém, tendência $(\mathrm{P}=0,06)$ de aumento linear nesta variável nas maiores ofertas de forragem. A média encontrada para a oferta de 4\% do PV/dia foi de $194 \mathrm{~mm}$, enquanto na maior oferta de forragem a média foi de $210 \mathrm{~mm}$. O comprimento final da folha (Tabela 1) variou com os ciclos de pastejo $(\mathrm{P}<0,0001)$, não sendo observada a interação entre os fatores
( $\mathrm{P}>0,05)$. De acordo com Gomide \& Gomide (1999), o comprimento final da folha é afetado principalmente pelo comprimento do pseudocolmo (envoltório de bainhas). Assim, quanto maior o comprimento do pseudocolmo, maior o espaço a ser percorrido pela folha para iniciar e completar sua emergência até alcançar sua expansão, determinando, portanto, seu maior comprimento. Apesar de o comprimento do pseudocolmo não ter sido avaliado neste experimento, o alongamento do colmo está relacionado ao tamanho do pseudocolmo, desde que a planta não esteja em estádio reprodutivo. Entretanto, o alongamento do colmo em um ciclo de pastejo tem reflexo no comprimento do pseudocolmo no ciclo subsequente. Desta forma é possível explicar o resultado obtido no comprimento final da folha, que foi maior nos terceiro e quarto ciclos, visto que as maiores taxas de alongamento de colmo foram obtidas no segundo e terceiro ciclos. Essa mesma explicação pode ser utilizada para discutir a tendência de aumento do comprimento da folha nas maiores ofertas de forragem, visto que o alongamento do colmo aumentou linearmente com aumento da oferta de forragem (Figura 2).

As densidades populacionais de perfilhos vegetativos, reprodutivos e totais variaram com a oferta da forragem $(\mathrm{P}<0,05)$ e os ciclos de pastejo $(\mathrm{P}<0,0001)$. No entanto, apenas na densidade de perfilhos vegetativos, a interação entre os fatores estudados foi significativa $(\mathrm{P}<0,05)$. Ao analisar o efeito da oferta de forragem em cada ciclo de pastejo (Tabela 2), não foi encontrado efeito $(\mathrm{P}>0,05)$ das ofertas nesta variável, porém foram observados efeitos $(\mathrm{P}<0,0001)$ dos ciclos de pastejo.

A densidade de perfilhos vegetativos não variou $(P>0,05)$ com os ciclos de pastejo nos piquetes sob a menor oferta de forragem, entretanto, nos piquetes sob as ofertas mais altas, valores mais altos dessa variável foram observados $(\mathrm{P}<0,05)$ no segundo ciclo de pastejo, como resultado da adubação nitrogenada realizada, visto que o suprimento de nitrogênio tem efeito positivo sobre o perfilhamento (Fagundes et al., 2006b). Embora não tenha

Tabela 2 - Densidade populacional de perfilhos vegetativos de capim-marandu em quatro ofertas de forragem e quatro ciclos de pastejo

\begin{tabular}{|c|c|c|c|c|c|}
\hline \multirow{2}{*}{$\begin{array}{l}\text { Ciclo de } \\
\text { pastejo }\end{array}$} & \multicolumn{4}{|c|}{ Oferta de forragem (\% do PV) } & \multirow[t]{2}{*}{$\mathrm{CV} \%$} \\
\hline & 4 & 7 & 10 & 13 & \\
\hline \multicolumn{6}{|c|}{ Perfilhos $/ \mathrm{m}^{2}$} \\
\hline 1 & $1025 \mathrm{Aa}$ & $787 \mathrm{Ba}$ & $1104 \mathrm{Ba}$ & $756 \mathrm{Ba}$ & 16,1 \\
\hline 2 & $1913 \mathrm{Aa}$ & 1493Аа & 1929Aa & 1159 АВа & 18,2 \\
\hline 3 & $1639 \mathrm{Aa}$ & $1696 \mathrm{Aa}$ & $1234 \mathrm{Ba}$ & $1623 \mathrm{Aa}$ & 19,9 \\
\hline 4 & $1058 \mathrm{Aa}$ & $1417 \mathrm{Aa}$ & $1371 \mathrm{Ba}$ & 996АВа & 14,5 \\
\hline
\end{tabular}

Médias seguidas da mesma letra minúscula na linha e maiúscula na coluna não diferem entre si $(\mathrm{P}>0,05)$ pelo teste Tukey. 
sido verificado efeito do ciclo de pastejo na densidade de perfilhos vegetativos na oferta de forragem de $4 \% \mathrm{do} \mathrm{PV} / \mathrm{dia}$, a mesma tendência obtida nas outras ofertas.

A densidade de perfilhos reprodutivos aumentou de forma quadrática $(\mathrm{P}<0,01)$ conforme a oferta de forragem (Figura 3). Nos piquetes com maior pressão de pastejo, houve melhor controle dos perfilhos reprodutivos, evidenciando a mais intensa decapitação de seus perfilhos vegetativos (Casagrande et al., 2004).

Não foi encontrado nenhum perfilho reprodutivo no primeiro ciclo de pastejo, em razão do corte de uniformização na fase pré-experimental, o qual propiciou grande renovação da população de perfilhos. Entretanto, com a sucessão dos ciclos de pastejo, ocorreu o aparecimento de perfilhos reprodutivos, principalmente no terceiro ciclo (194 perfilhos $/ \mathrm{m}^{2}$ ). A alta densidade de perfilhos vegetativos no segundo ciclo de pastejo, aliada ao estímulo da aplicação de nitrogênio, provavelmente intensificou o processo de desenvolvimento dos perfilhos, consequentemente, maior número de perfilhos atingiu o estádio reprodutivo no terceiro ciclo. No último ciclo, houve redução da densidade de perfilhos reprodutivos devido à morte de perfilhos, o que determinou a redução da densidade de perfilhos totais.

A densidade de perfilhos totais variou $(\mathrm{P}<0,05)$ com a oferta de forragem ajustando-se ao modelo gerado por uma equação de segundo grau (Figura 3), com ponto de máxima

(a)

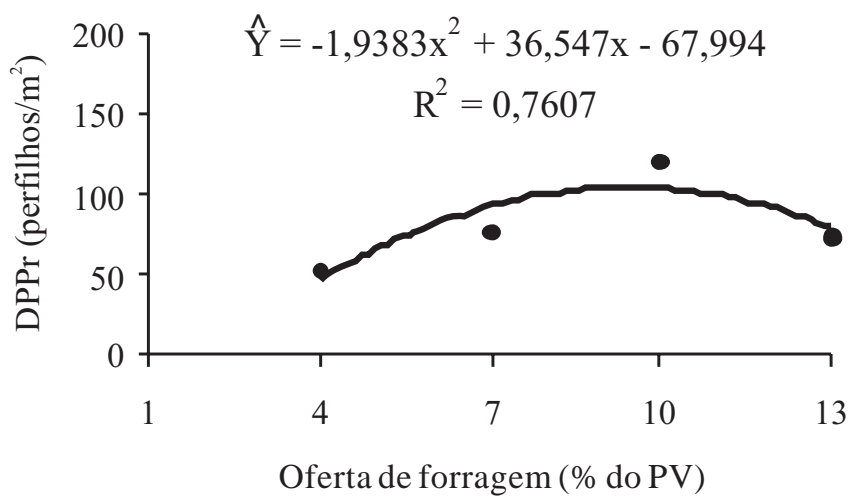

correspondendo à oferta de forragem de 7,1\% doPV/dia. A acentuada redução da densidade de perfilhos totais na maior oferta de forragem pode ser atribuída à maior altura do dossel (Figura 2), a mais intensa interceptação de luz pelo dossel e ao consequente comprometimento do processo de perfilhamento pela baixa intensidade e qualidade da luz incidente na base do dossel (Chapman \& Lemaire, 1993). Esses dados corroboram as conclusões de Skinner \& Nelson (1992) de que o perfilhamento, em dosséis muito densos, é inferior ao potencial determinado pela taxa de aparecimento de folha, em decorrência do efeito de forte competição entre indivíduos por assimilados e luz.

No primeiro ciclo de pastejo, foi observada a mais baixa densidade de perfilhos totais durante todo período experimental (Tabela 1). No segundo e terceiro ciclos de pastejo, constatou-se aumento significativo dessa variável, fatos atribuíveis ao efeito favorável da aplicação de nitrogênio no início do segundo ciclo sobre o perfilhamento (Fagundes et al., 2006b). Desta forma houve aumento na densidade de perfilho vegetativo no segundo ciclo e esse aumento foi responsável pela alta densidade de perfilhos totais (vegetativos + reprodutivos). No terceiro pastejo, houve intenso aumento na densidade de perfilhos reprodutivos (Tabela 2), mantendo a densidade de perfilhos constante nesses períodos. No entanto, verificou-se redução dessa variável no último pastejo, possivelmente causada pela morte desses perfilhos.

(b)

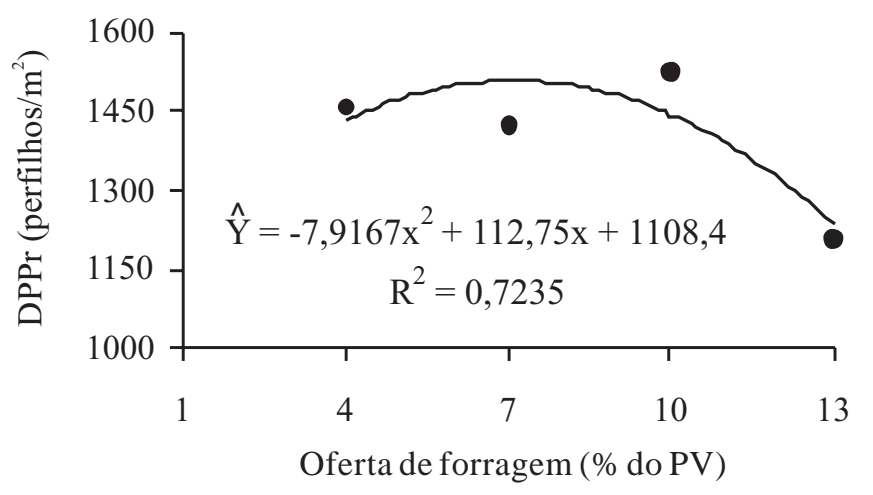

Figura 3 - Densidade populacional de perfilhos reprodutivo (a) e totais (b) de capim-marandu manejado com quatro ofertas de forragem.

\section{Conclusões}

O alongamento de colmos e a densidade de perfilhos são as variáveis morfogênicas e estruturais mais afetadas pela intensidade e sucessão dos pastejos (desfolhas). As condições ambientais têm maior influência sobre as características morfogênicas e estruturais em comparação a ações de manejo, como manipulação da oferta de forragem. Ofertas de forragem de $4 \%$ do PV/dia promovem menor alongamento de colmo e tendem a reduzir as perdas por senescência. 


\section{Referências}

ANDRIOLI, I.; CENTURION, J.F. Levantamento detalhado dos solos da Faculdade de Ciências Agrárias e Veterinárias de Jaboticabal. In: CONGRESSO BRASILEIRO DE CIÊNCIA DO SOLO, 27., 1999, Brasília. Anais... Brasília: Sociedade Brasileira de Ciência do Solo, 1999. p.32.

BARBOSA, R.A.; NASCIMENTO JR., D.; EUCLIDES, V.P.B. et al. Características morfogênicas e acúmulo de forragem do capimTanzânia (Panicum maximum Jacq. cv. Tanzânia) em dois resíduos forrageiros pós-pastejo. Revista Brasileira de Zootecnia, v.31, n.2, p.583-593, 2002.

BIRCHAM, J.S.; HODGSON, J. The influence of sward condition on rates of herbage growth and senescence in mixed sward under continuous stocking management. Grass and Forage Science, v.38, n.4, p.323-331, 1983.

CÂNDIDO, M.J.D.; GOMIDE, C.A.M.; ALEXANDRINO, E. et al. Morfofisiologia do dossel de Panicum maximum cv Mombaça sob lotação intermitente com três períodos de descanso. Revista Brasileira de Zootecnia, v.34, n.2, p.406-415, 2005.

CASAGRANDE, D.C. Características morfogênicas do dossel de Brachiaria brizantha (Hochst ex. A. Rich.) cv. Marandu Manejada com diferentes ofertas de forragem sob lotação intermitente. 2007. 77f. Dissertação (Mestrado em Zootecnia) - Faculdade de Ciências Agrárias e Veterinárias - Universidade Estadual Paulista, 2007.

CASAGRANDE, D.R.; MISTURA, C.; FONSECA, D.M. et al. Densidade populacional de perfilhos e índice de área foliar do capim-elefante submetido a diferentes alturas de resíduo póspastejo. In: GRASSLAND ECOPHYSIOLOGY AND GRAZING ECOLOGY, 2., 2003, Curitiba. Anais... Curitiba, 2004. (CD-ROM).

CHAPMAN, D.F.; LEMAIRE, G. Morphogenetic and structural determinats of plant regrowth after defoliation. In: BAKER, M.J. (Ed.). Grassands for our world. Wellington: Sir Publishing, 1993. p.55-64.

CORSI, M.; BALSALOBRE, M.A.; SANTOS, P.M. et al. Base para o estabelecimento de manejo de pastagens de Braquiária. In: SIMPÓSIO SOBRE MANEJO DE PASTAGENS, 11., 1994, Piracicaba. Anais... Piracicaba: FEALQ, 1994. p.249-266.

DA SILVA, C.C.F; BONOMO, P.; PIRES, A.J.V. et al. Características morfogênicas e estruturais de duas espécies de braquiária adubadas com diferentes doses de nitrogênio. Revista Brasileira de Zootecnia, v.38, n.4, p.657-661, 2009.

DA SILVA, S.C.; NASCIMENTO JR., D. Avanços na pesquisa com plantas forrageiras tropicais em pastagens: características morfofisiológicas e manejo do pastejo. Revista Brasileira de Zootecnia, v. 36, p.121-138, 2007 (supl. especial).

DA SILVA, S.C.; BUENO, A.A.O; CARNEVALLI, R.A. et al. sward structural characteristics and herbage accumulation of Panicum maximum cv. mombaça subjected to rotational stocking managements”. Scientia Agricola, v.66, n.1, p.8-19, 2009.

DAVIS, A. Leaf tissue remaining after cutting and regrowth in perennial ryegrass. Journal of Agricultural Science, v.82, p.165-172, 1974

FAGUNDES, J.L.; FONSECA, D.M.; MISTURA, C. et al. Características morfogênicas e estruturais do capim-braquiária em pastagem adubada com nitrogênio avaliadas nas quatro estações do ano. Revista Brasileira de Zootecnia, v.35, n.1, p.21-29, 2006a.

FAGUNDES, J.L.; FONSECA, D.M.; MORAES, R.V. et al. Avaliação das características estruturais do capim-braquiária em pastagens adubadas com nitrogênio nas quatro estações do ano. Revista Brasileira Zootecnia, v.35, n.1, p.30-37, 2006b.

GOMIDE, C.A.M.; GOMIDE, J.A. Morfogênese de cultivares de Panicum maximum Jacq. Revista Brasileira de Zootecnia, v.29, n.2, p.341-348, 2000.

GOMIDE, J.A.; GOMIDE, C.A.M. Fundamentos estratégias do manejo de pastagens. In: SIMCORTE - SIMPÓSIO DE PRODUÇÃO DE GADO DE CORTE. 1., 1999, Viçosa, MG. Anais... Viçosa, MG, 1999. p.179-200.

GONÇALVES, A.C. Características morfogênicas e padrões de desfolhação em pastos de capim-Marandu submetidos a regime de lotação continua. 2002. 124f. Dissertação (Mestrado em Agronomia - Ciência Animal e Pastagens) - Escola Superior de Agricultura "Luiz de Queiroz"/Universidade de São Paulo, Piracicaba.

HODGSON, J. Grazing manajement: science into pratice. Longman Group, U.K.: Longman Scientific and Technical, 1990. 203p.

MACHADO, L.; FABRÍCIO, A.C.; ASSIS, P.G.G. et al. Estrutura do dossel em pastagens de capim-marandu submetidas a quatro ofertas de lâminas foliares. Pesquisa Agropecuária Brasileira, v.42, n.10, p.1495-1501, 2007.

OMETTO, J.C. Bioclimatologia vegetal. São Paulo: Ceres, 1981. 440p

PARSONS, A.J.; LEAFE, E.F.; COLLET, B. et al. The physiology of grass production undergrazing: 2- Photosynthesis, crop growth and animal intake of continuosly grazed swards. Journal of Applied Ecology, v.20, n.1, p.127-139, 1983.

PEDREIRA, B.C.; PEDREIRA, C.G.S.; DA SILVA, S.C. Acúmulo de forragem durante a rebrotação de capim-xaraés submetido a três estratégias de desfolhação. Revista Brasileira de Zootecnia, v.38, n.4, p.618-625, 2009.

PETERNELLI, M. Características morfogênicas e estruturais do capim-braquiarão [Brachiaria brizantha (hochst ex a. rich.) stapf cv. Marandul sob intensidades de pastejo. 2003. 79f. Dissertação (Mestrado em Zootecnia) - Faculdade de Zootecnia e Engenharia de Alimentos/Universidade de São Paulo. Pirassununga.

SBRISSIA, A.F. Morfogênese, dinâmica do perfilhamento e do acúmulo de forragem em pastos de capim-Marandu sob lotação contínua. 2004. 171f. Tese (Doutorado em Agronomia - Ciência Animal e Pastagens) - Escola Superior de Agronomia “Luiz de Queiroz”/Universidade de São Paulo, Piracicaba.

SKINNER, R.H.; NELSON, C.J. Estimation of potential tiller production and site usage during tall fescue canopy development. Annals of Botany, v.70, p.493-499, 1992.

SOLLENBERGER, L.E.; CHERNEY, D.J.R. Evaluating forage production and quality. In: BARNES, R.F.; MILLER, D.A.; NELSON C.J. (Eds.). Forages: The science of grassland agriculture. Ames: Iowa State University. Press, 1995. v.2, p.97-110.

STATISTICAL ANALYSIS SYSTEM - SAS. SAS/STAT user's guide: statistics. 4.ed. Version 8.2. Cary: 2001, v.2. 943p.

ZEFERINO, C.V. Morfogênese e dinâmica do acúmulo de forragem em pastos de capim-marandu [Brachiaria brizantha (Hochst. ex. A. Rich) cv. Marandu] submetidos a regimes de lotação intermitente por bovinos de corte. 2006. 193f. Dissertação (Mestrado em Agronomia - Ciência Animal e Pastagens) - Escola Superior de Agronomia "Luiz de Queiroz"/Universidade de São Paulo, Piracicaba. 